\title{
Chapter 12 \\ Competencies, Culture, and Change: A Model for Digital Transformation in K-12 Educational Contexts
}

\author{
Angela Elkordy and Jessica Iovinelli
}

\subsection{Introduction}

The process of change in learning organizations can seem unpredictable or random. Great ideas can inexplicably languish during implementation, whereas ineffective practices or misconceptions can spread and take hold within hours. A systems perspective to organizational change can shed light on the seemingly disconnected processes and outcomes of change, as well as an understanding of change versus transformation. As K-12 organizations increasingly adopt digital tools and technologies for communications, knowledge creation and management, as well as learning, the knowledge of concepts such as innovation diffusion, technology adoption models, and change management can help leaders to plan for success. The learning sciences - an interdisciplinary field grounded in findings from the cognitive sciences, social psychology, neuroscience, and educational psychology - can shed light on the human elements of change within systems and the why of processes. The science of learning is a translational science; findings from more traditional research are not easily applied in naturalistic settings to inform instructional practices, nor provide insights to organizational culture. It is crucial, however, to understand the impact of complex, interconnecting systems in learning organizations to distinguish between managing change and leading transformation. The learning sciences function as a bridge, so to speak, between research and its implication to practice in different contexts.

Understanding the principles behind strategic leadership that are necessary to effect change in learning organizations is critical to enact new initiatives or widespread transformation successfully. For example, there is a significant body of literature describing the importance of social or the human elements of change in learning organizations, including aspects of culture, community, and context. A

\footnotetext{
A. Elkordy $(\square) \cdot$ J. Iovinelli

National College of Education, National Louis University, Chicago, IL, USA

e-mail: aelkordy@nl.edu 
learning sciences-informed view, however, can illuminate the why or the essential principles of social and communications systems crucial for success. This scenario is analogous to knowing that conversations are necessary versus an understanding of the kinds of interactions and communications needed, for whom as well as when to move change forward in a productive manner. Furthermore, an understanding of effective principles - as well as strategies - necessary for transformation allows for greater insight when troubleshooting problems as they arise.

Despite the importance of learning in learning organizations, models of change do not look deeply into these important components, nor carefully examine the interactions within the system functioning as forces. Existing models of technology adoption, such as the diffusion of innovation (DOI) (Rogers 1995) or the Technology, Organization and Environment (TOE) model (Tornatzky and Fleischer 1990), focus upon a high-level systems view of the components and processes of change. For example, the TOE framework views the overall system as a collection of three subsystems of context - the technological, organizational, and environmental contexts. In a review of the literature on technology adoption models, scholars Oliveira and Martins (2011) described several variants of the DOI and TOE models.

The successful infusion of appropriate instructional technologies in K-12 contexts requires strategic planning and significant leadership support. Until recently, however, K-12 leadership behaviors and decisions, particularly creating and sharing a vision, setting instructional goals or expectations, and organizational culture, has mostly been ignored as contributing factors in the degree of success in building or district technology implementation. As a result, the interactions between building leaders and school staff have not been studied significantly as influencing the diffusion and subsequent adoption of instructional technologies throughout a building. The International Society for Technology in Education (ISTE), an international educational technology organization, contributed to the work of understanding the leadership supports necessary for transformation. In its 2018 refresh of standards for education leaders, ISTE includes criteria such as Visionary Planner and Systems Designer in recognition of the complexity of the leadership supports required for disruptive, transformative change (ISTE 2018).

In this chapter, we discuss digital transformation and second-order change from a learning science-informed perspective. For example, educational leaders in K-12 and higher education contexts are encouraged to communicate extensively with stakeholders in preparation for new initiatives or changes. Usually, the reasoning behind leader communications is primarily to inform - that is, to convey the rationale, intent, and timeline for the changes. In general, the role of communications as influential and iterative, interconnected events is underestimated and, as a result, is neither adequately considered nor leveraged. Information from the learning sciences, however, can share a more nuanced understanding of the principles at work in effective communications, for example, the necessity for conveying and converging stakeholders' mental models, that is, individuals' understanding of concepts and their interconnections. A fundamental mistake is assuming that team members hold similar conceptualizations of ideas in a community context, such as K-12 learning organizations. It is also important to understand the role and impact of participants' 
emotions, learning, and work-related needs as well as power relationships and interactions. We present a case study that identifies positive steps toward digital transformation in schools and implications for the work to come.

\subsubsection{Digital Transformation and Second-Order Change}

In an organizational context, the process of change relies upon many external factors, including methods, tools, and systems. First-order change may include revised processes and products. It relies upon existing knowledge and skills to effect, is consistent with "prevailing norms and values," and occurs within the parameters of familiar paradigms (Waters and Marzano 2006, p. 18). Although schools and organizations have been using technology to manage information for years, the focus now is less on data collection and organization itself, and more on data usage to further strategic goals and targets as well as for instruction. This focus requires a shift in mindset throughout organizational systems to realize the potential of technology for everyday organizational needs such as teaching and learning, communicating, data acquisition, storage, and processing. In K-12 educational contexts, leaders must first experience this shift in perspective to successfully guide other stakeholders.

For transformation to occur, however, requires second-order change that involves the organization as a whole, a system of systems. "Any digital transformation initiative will only succeed if there is a holistic approach to standardize the way that information and content is managed, used, and shared across the organization" (OnBase 2017, p. 2). Importantly, transformation in an educational setting also requires the use of digital tools to be leveraged as cognitive tools to scaffold, assess, and facilitate learning and knowledge generation. Digital transformation entails disruption - significant change at a fundamental level - resulting in a paradigm shift with regard to conceptualization and reorganization of mental models or shared understanding. Critical to this process of disruption and rebuilding is thinking about how the unique affordances of digital technologies can be leveraged to meet newly envisioned strategic goals and objectives. We propose an updated model of change for digital transformation. In particular, digital transformation should be considered within existing frameworks in the areas of organizational context, learning, leadership, and people and culture, which we discuss next in a brief review of the literature.

\subsection{Literature Review}

In this section, we consider three intersecting areas for the strategic planning and implementation of a wide-scale, disruptive change in educational settings: organizational context, leadership, and people. 


\subsubsection{Organizational Context}

When analyzing factors necessary for digital transformation, organizational context is paramount to determining behavioral barriers to such large-scale systemic change and tailoring design and implementation accordingly. Context, as defined by Wagner, would be the larger organizational systems, the reality of the community, and its history that create the current state of the organization (Wagner et al. 2006). To create the right conditions or the "external architecture surrounding student learning, the tangible arrangements of time, space, and resources" (Wagner et al. 2006, p. 101) imperative for implementing large-scale transformation, context is critical for each initiative to be successful and sustainable.

The Technology-Organization-Environment (TOE) framework (2012) describes technological, organizational, and environmental contexts as three different elements of a firm's "context influence adoption" (Baker, p. 232). In this model, developed in 1990 by Tornatzky and Fleischer, organizational context is described as "the characteristics and resources of the firm, including linking structures between employees, intra-firm communication processes, firm size, and the amount of slack resources" (Baker 2012, p. 233). In their research, Tornatzky and Fleischer categorized organizational context into formal and informal linking structures, communication processes, size, and slack. They found benefits of both an organic and decentralized organizational structure as well as a mechanical structure in regard to adoption and implementation of innovation. Decentralized organizations rely on teams, fluidity, and flexibility in groupings of employees, and promotion of communication, which leads to the adoption of innovation. At the same time, mechanistic structures provide the strategy necessary for implementation (Baker 2012). The key was knowing the organizational context to leverage it for optimal transformation.

Knowledge of the organizational context was also identified as highly relevant in a study authored by Evans et al. (2017) on integrated care initiatives and transformation. The researchers found that "organizational contexts are rarely described, understood, or measured with sufficient depth and breadth in empirical studies or in practice" (p. 1). Through their study, they set out to prove that tailoring programs to respond to the local and organizational contexts impacted their degree of success. Semi-structured interviews and a multitude of surveys were used to create, revise, and validate a conceptual framework called the Context and Capabilities for Integrative Care (CCIC) framework for the study of organizational context in integrated care delivery situations. The final framework consisted of 18 organizational factors that could be sorted into three broad categories: basic structures, people and values, and key processes. The CCIC framework can "help inform our understanding of the dynamic interactions and evolution of organizational context factors" by providing a standardized method to compare multiple initiatives. Furthermore, the framework "can enhance our understanding of the influence of these factors, support the transfer of best practices, and help explain why some integrated care initiatives succeed and some fail" (Evans et al. 2017, p. 12). 
Fonseca and Domingues (2017) in describing key actions for digital age contexts suggest to

monitor the organizational (internal and external) context and identify the key issues that affect the organization's ability to deliver quality products and satisfy their customers and key stakeholders, and to plan, design, implement and control change in an effective and timely manner. (p. 443)

They define organizational context as "a pattern of shared values and assumptions within an organization which enables this to operate" (p. 445). They concluded that in a dynamic area such as digital transformation, where technology is continually updating and evolving, organizations could risk "losing the competitive edge to more agile and innovative competitors" (p. 446). Furthermore, Fonesca and Domingues state that a lack of understanding of the organizational context could easily prevent the company from making systemic changes. An online survey was sent to over 5,000 auditors through which quantitative data were collected during the study, then analyzed, finding a positive correlation between "the capability to understand the context and both the ability to change and the achievement of improved performance and results" (p. 453).

\subsubsection{Leadership}

In the last decade, the concept of leadership has significantly changed. There has been a broadening of the scope of technology-related knowledge in a K-12 organizational or school setting. The challenges have moved away from simply acquiring devices, configuring infrastructure, and a basic level of operational skill to challenges of aligning the implementation to goals, increasing staff capacity, and shaping a supportive culture. These shifts have brought to light the lack of informed leadership (Flanagan and Jacobsen 2003; Ritchie 1996) and the need for leadership to accept the challenge of creating the conditions in which employees and staff are empowered to experiment and take risks with technology (Iovinelli 2020, p. 38).

Many nationally recognized organizations have connected the importance of leadership in digital transformation. Because of change in current teaching and learning environments, the International Society for Technology in Education (ISTE) has created sets of standards for students, educators, education leaders, coaches, and computer science educators. These standards, regularly revised, "act as a roadmap for bold, innovative educators and education leaders to re-engineer their schools and classrooms for digital age learning no matter where they fall on the journey to meaningful, effective ed. tech integration" (ISTE 2018, para. 3).

Initially titled Standards for Administrators in 2002, the ISTE Standards for Education Leaders were created to promote the effective integration of technology into the curriculum. ISTE realized the importance of personal learning communities (PLCs) and shared leadership, which was reflected in title change as a way to reflect the movement from top-down management to developing leaders, regardless of 
title, who leverage technology to build a favorable learning landscape (ISTE 2018; Iovinelli 2020). The latest refresh of the standards in 2018, now called Standards for Education Leaders, has become more targeted. Specifically, the guidelines identify the "knowledge and behaviors required for leaders to empower teachers and make student learning possible" (ISTE 2018, para. 1). The standards highlight public areas of struggle and the leadership skills necessary in education today. A key focus is how leaders can demonstrate technology is essential to support digital age learning as a(n): equity and citizenship advocate, visionary planner, empowering leader, systems designer, and connected learner (ISTE 2018).

On a more general level, LearningForward (2011) created standards for professional learning pertaining to the ability for leaders to "develop their own and other's capacity to learn and lead professional learning, advocate for it, provide support systems, and distribute leadership and responsibility for its effectiveness and results" (para. 1). Through research and evidence-based practice, a Professional Learning framework was created that includes learning communities, leadership, resources, data, learning designs, implementation, and outcomes to provide progress toward a goal. The leadership component of the framework focuses on developing a capacity for learning and leading, advocating for professional learning, and creating support systems and structures, all of which are needed to turn leaders into agents of change for digital transformation (LearningForward 2011).

\subsubsection{People}

The quality and success of learning, leadership, and change processes hinge upon the stakeholders - the people involved. Understanding the interactions and impact of people within systems necessitates an insightful awareness of organizations' culture as defined by Wagner et al. (2006) as the "shared values, beliefs, assumptions, expectations, and behaviors related to student learning, teachers and learning, instructional leadership, and the quality of relationships within and beyond the school" (p. 102). Evans et al. (2017) focused upon integrated care initiatives and transformation in a study. The authors defined a framework of factors that could impact the success of an initiative, which also cited people and values with a focus on patient-centeredness and engagement, commitment to learning, and readiness for change.

The challenge of digital transformation has moved away from merely acquiring devices, infrastructure, and a basic level of operational skill to aligning implementation to school or organizational goals, expanding staff capacity, and shaping a supportive culture. If the countless attempts at systemic reform have taught us anything, it is that "policy change without cultural change is an exercise in futility and frustration" (Reeves 2009, p. 37). A person's background, culture, values, and traditions affect the way they work, learn, and respond, which makes human systems unpredictable and dynamic. Digital transformation has implications for all social systems involved, namely the need to increase capacity in preparation programs, but also in 
the workplace. The ISTE Standards for Educators, Coaches, and Students (2018) highlight a system that embraces shared learning, trust, and empowerment while focusing on expanding the capacity of each stakeholder group. These standards, though intended for educators, apply to the overall concept of rethinking the usage of technology in learning organizations and people involved, an area often neglected in systemic change.

\subsection{Implementing the Model: A Case Study}

An empirical study of digital transformation in schools was completed in Modern Mind Community Unit School District (CUSD). The field of educational technology lends itself to both quantitative and qualitative research as both methods have the potential to create new, actionable insights for improving technology usage for student learning (Patton 2008). Through discussions with the intended users of this study, the decision was made to ensure a comprehensive evaluation by balancing the limitations of one data type with the strengths of another, which involved using both qualitative and quantitative methods (Fig. 12.1).

The data collected centered around two areas of research concerning technology implementation and digital transformation in K-12 learning organizations: professional development and leadership. A survey was conducted to collect data on educator perceptions about the effectiveness of the multiple formats of professional development offered throughout the year. Questions included participants' opinions about the learning experiences' impact on technology implementation, as well as

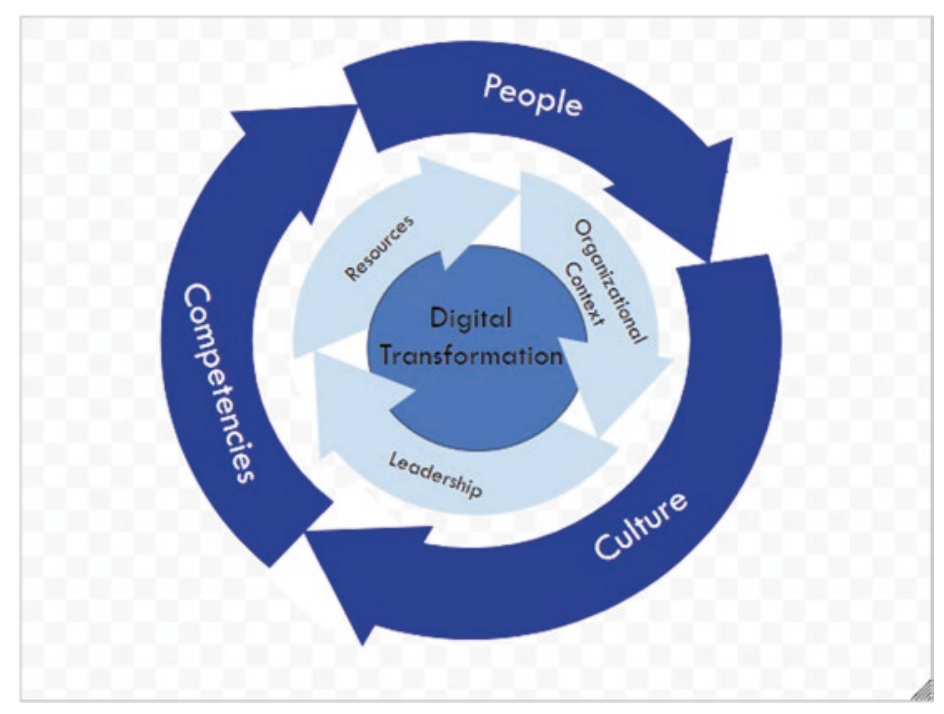

Fig. 12.1 The proposed model of digital transformation 
ideas or suggestions for additional professional development formats and leadership supports. The questions were modeled after a core set of features for professional development defined by Desimone (2009), Garet et al. (2010), and Penuel et al. (2011) while also reflecting the Standards for Professional Learning framework created by LearningForward (2011). In conjunction with the professional development survey, staff interviews provided additional data regarding the perceived role of technology in education and the level of success of implementation in Modern Mind CUSD. To describe and quantify leadership behaviors and gather administrative perceptions of their influence, data from the 2018 and 2019 BrightBytes surveys and public data from the 2017 and 2019 5Essentials survey were analyzed, along with interviews of administrators. Questions were structured using the newly revamped 2018 ISTE Standards for Education Leaders (formerly known as the ISTE Standards for Administrators) as a framework.

Classroom observations also took place to triangulate perceptions with in-class practices in the areas of professional development and leadership. Correlational analyses using the observation data determined the relationships between total score, years of experience, and participation in professional development formats to examine how one or more of these variables may change with others. Along with the correlations, cluster analyses identified groups of similar participants based upon the variables and data collected. The purpose of these analyses was to use further quantify progress toward digital transformation and to aid in prioritizing recommendations to continue to move forward (Patton 2008).

\subsubsection{Stuck in the Analog}

Modern Mind CUSD is a district of five schools with a total of just under 3,000 students in grades pre-kindergarten through 12. In addition to the district office, there is one early childhood center (ECC), two elementary schools (Innovate and Integrate Elementary), one middle school (Interact Middle), and one high school (Modern Mind High School). These schools serve the residents of Mente, a near west suburb of a large Midwestern city with a population of approximately 24,000. Mente has a large Italian population and has recently seen an influx of Polish, Ukrainian, and Mexican immigrants. Mainly residential, it is known for not only its welcoming family feel but also its high taxes.

The use of digital tools and technologies was not a large part of the culture or practice of Modern Mind CUSD before 2016. The extent of technology available to students in each of the five buildings was limited to a few computer labs, a library lab, and a few laptops per classroom at the primary grade levels. The articulated vision of the district for the use of these resources was vague and almost nonexistent. In the prior 20 years, there were only three significant school-wide initiatives: a math lab for the elementary schools, a new science wing at the high school, and a reading initiative involving the book Three Cups of Tea by author Mortenson \& Relin (2007). Also, in those 20 years, leadership turnover was high, with five 
superintendents total, three of whom served in the last decade. The instability in leadership contributed to a belief in the community and among staff that any project or initiative would not be followed-through nor adequately funded as part of a larger picture or vision. As Modern Mind approached the 2016-2017 school year, significant decisions were necessary for the continued growth of the district. The school leadership, including its board and superintendent, determined several areas for substantial growth in the following school year. These areas included: technology services and tools, curriculum articulation and opportunities, student support services, maintenance and improvement of facilities, district operations, and community outreach.

Former high school assistant principal, Dr. James Namow, was promoted to assistant superintendent in 2016 and was involved heavily in the revision of the goals to address the needs identified. Also, in cooperation with the resting school board of education, Dr. Namow helped create a new vision to "inspire minds in the pursuit of excellence" supported by the collaborative mission to cultivate "individualized social-emotional learning processes, rigorous academics fostering inquisitive minds prepared for critical thinking, active, engaged partnerships with the community and parents, and innovative uses of 21st-century technologies for teaching and learning" (omitted for confidentiality 2019, para. 2). Dr. Namow hired a Director for Instructional Technology, Ms. Angela White, and the two administrators were tasked with the majority of the strategic planning for the roll-out of a districtwide technology initiative that would serve as the foundation for the other identified areas of growth. They both knew that in order to move toward digital transformation in the district, the focus had to be overarching goals for technology implementation as a way to improve student achievement and academic growth, enhance the curriculum, and create an environment that supports differentiated and personalized learning. To accomplish these goals, Dr. Namow and Ms. White focused upon the first layer of elements necessary for digital transformation - the organizational context of Modern Mind, that is, the role of leadership, and the resources both available and desired. These elements would be essential to support the people, increase competencies and expand capacity, and to create the culture conducive to systemic change and digital transformation. This approach was necessary in order to move the needle for learning and to avoid the common pitfall of continuing to teach in the same manner as before, that is, first-order change, hoping that technology alone will magically make it more meaningful and effective.

\subsubsection{Elements of Organizational Context as a Barrier}

The context of Modern Mind CUSD, as defined by Wagner, would be the larger organizational systems, the reality of the community, and its history - all of which create the current state of Modern Mind CUSD (Wagner et al. 2006). Knowing the staff and the school or district context is imperative when implementing large-scale transformation and to create the right conditions or the "external architecture 
surrounding student learning, the tangible arrangements of time, space, and resources" (Wagner et al. 2006, p. 101). A deep understanding of the context is critical for an initiative to be successful and sustainable. The district must provide the support necessary to continue to alter pedagogy to prepare learners to be active, creative, knowledgeable, and ethical participants in our global society (U.S. Department of Education 2017). Modern Mind CUSD is a PreK-12 district composed of five schools, 19 administrators, and 215 staff members. The longevity of the staff service is in stark contrast with the high turnover rate for administrators, especially in recent years, making stability a challenge for leadership and staff at all levels. The historical recount of administrative turnover has led to a lack of grounded relationships, causing a trust gap. Similar to an achievement gap, a trust gap takes time and strategy to eradicate, as it is a complex force that is essential and invisible. Continuous, job-embedded professional development opportunities were plentiful, allowing for meaningful learning that was mindful of the value of teachers' time, and that allowed for personalization of learning for adults. An essential element was missing, however - the movement from top-down management to a practice of developing leaders, regardless of title, who could leverage technology to build a positive learning landscape and realize the possibilities of a digital transformation.

\subsubsection{Building Leadership Able to Create and Sustain the Change}

Dr. Namow and Ms. White were aware of the importance that "education leaders [have] personal experience with learning technologies, an understanding of how to deploy these resources effectively, and a community-wide vision for how technology can improve learning" (U.S. Department of Education 2017, p. 42). In contrast to a focus solely on practical responsibilities and management of the status quo, leaders need to become agents of change, capable of driving shifts in instructional paradigms, as well as changes in culture. The International Society for Technology in Education (ISTE) Standards for Education Leaders highlight the need for educational leaders who are working to attain authentic digital transformation to demonstrate technology usage to support digital age learning in several ways. The guidelines require educational leaders to advocate for equity and citizenship, as well as being visionary planners, empowering leaders, systems designers, and connected learners (ISTE 2018).

In the study, one measure used to analyze leadership factors was the 5Essentials survey. Created by the Illinois State Board of Education (ISBE), this survey identifies five indicators that lead to improved outcomes for all students, as measured by improved attendance and substantial test score gains. These indicators include effective leaders, collaborative teachers, involved families, supportive environments, and ambitions instruction. The BrightBytes survey is another form of data used. It is collected by a company that provides data collection for technology integration, using research-based data analysis to understand better the impact that technology is having on student learning in schools (BrightBytes 2019). Modern Mind CUSD uses the Teaching and Learning module, which focuses on the Council for Advancement and 
Support of Education (CASE) framework of classroom, access, skills, and environment to make data-driven decisions. Through synthesizing data collected from the 5Essentials 2017 and 2019 data, the BrightBytes 2018 and 2019 survey data, and perception surveys, the study had several findings. One of the results is that the Modern Mind community operated under the belief that their school leaders lack the capacity for instructional leadership, particularly in providing useful feedback and support. Analysis of the survey data revealed the perceptions that leadership should be a resource, maintain communication, provide differentiated support, and create a culture of learners. Leadership's ability to set specific goals to help prioritize a focus, to set targets for learning, and to create accountability did not meet respondents' needs. Through the evaluation process, Dr. Namow and Ms. White found that only one of the six administrators cited a specific goal to increase personal technology capacity, and only one administrator having a school-wide goal in technology. However, even these goals lacked specificity. Instructional leadership is a critical aspect of school leadership, where measurable goals or objectives must be in place, not only for technology implementation but also for overall school improvement. The National Education Technology Plan synthesized the most recent available research on future-ready leadership and identified "four key focus areas of effective leadership: collaborative leadership, personalized student learning, robust infrastructure, and personalized professional learning" (U.S. Department of Education 2017, p. 43). School leaders without these characteristics, a basic knowledge of technology, an understanding of the power it has to transform learning, and the ability to articulate a vision for how technology can support learning goals will ultimately become yet another barrier to successful technology integration.

\subsubsection{Using Resources to Begin Moving Forward}

Dr. Namow and Ms. White worked hard to ensure that resources to support the shift to digital transformation were abundant and available to all staff, with the majority of the effort placed upon certified teaching staff and administration. Professional development was designed and facilitated by Ms. White and included half- and fullday sessions, teacher coaching, online self-guided instruction, cohort studies, coordinated site visits, and conferences, seminars, certifications, and degree program opportunities. Title I funding was used to provide funding for substitute teachers, and the staff was allowed to opt into as little or as much professional development as they deemed necessary for their professional practice. An influential district technology committee was in place that actively surveyed the needs of staff and students. The committee guided professional development topics and schedules, piloting tools and programs for the district, selecting devices, developing necessary policies and procedures associated with the migration to $1: 1$, and designing events aimed at keeping the community involved with the initiative as participants and decision-makers. 


\subsubsection{The People, the Competencies, the Culture}

When approaching sizeable systemic change like digital transformation, it is essential to remember that educational staff members are not blank slates. In planning, it is necessary to consider prior knowledge and experiences staff may have in a wide array of content areas ranging from tenure to non-tenure, elementary to graduate studies. The learning sciences describe learners' prior knowledge as pivotal to new learning. Digital transformation is the ability to adopt digital technologies, methodologies, and mindsets while embracing technology as a tool to leverage work. Neglecting to provide personalized professional learning in a culture that "engages in collaborative inquiry to build the capacity of both the staff and the leadership" (U.S. Department of Education 2017, p. 45) is a significant roadblock in leveraging technology for student learning and choice in how they demonstrate understanding. Professional development is essential to growing in any organizational context; however, in the needs assessment for the study, staff identified different strengths, backgrounds, and areas of vulnerability. Attending professional development that is not personally relevant has a profound impact on learner engagement and, therefore, the subsequent implementation of new practices, which impacts student engagement. Providing personalized learning for staff not only prevents disengagement but also demonstrates that time, expertise, and growth is valued (Whitehead et al. 2013). Professional development efforts by Dr. Namow and Ms. White were comprehensive. Much of the feedback regarding the current state of professional development in Modern Mind CUSD highlighted the variety of offerings from the district and the positive impact that choice was having on teaching practices.

Knowing that the most significant professional development efforts could fail in an organizational culture of fear, Dr. Namow and Ms. White continued the focus on the ISTE Standards as a framework for change, highlighting a system that embraces shared leadership, trust, and empowerment. Breaking away from a traditional hierarchical model of leadership, a top-down, pyramid-shaped design with a clear chain of command, Dr. Namow, and Ms. White worked to cultivate shared leadership. Systemic change is too complex to be addressed in isolation. A culture in which influence, authority, and decision-making are shared and promoted throughout the school is required, having an impact on the district's context as well as teacher and leader competencies. Not only do the people in formal leadership roles have leadership capabilities but so do the teachers, staff, parents, and students, and shared leadership will leave stakeholders viewing themselves less as independent contractors, and more as a company (Whitehead et al. 2013). Each person needed to put aside individual agendas for the greater good of student learning.

Fear of failure acts as a substantial barrier to technology implementation and experimenting with learning from whatever format of professional development. Error should not be reprimanded or even simply tolerated. In the process of change, failure is expected - "More importantly, it is welcomed and celebrated, thereby communicating to teachers that they can be secure in their role as practicing learners, similar to a practicing physician or a practicing attorney, to confidently 'learn, re-learn, and explore knowledge and understanding"' (Smith and Smith 2015, p. 35). 


\subsubsection{A Few Adjustments}

In education, whether relating to people or reform initiatives, new resources and expectations should not be merely added to existing, outdated educational paradigms to effect meaningful change in relationships. Educators and leaders need to confront tradition and discontinue the practice of completing for compliance. Dr. Namow and Ms. White have identified obstacles to digital transformation in Modern Mind. They are working to create the conditions in which technology is leveraged to empower learners to determine the right questions rather than simply providing answers. Technology and thoughtful teaching, in general, can energize learners and foster exploration. Digital tools can inspire creative, problem solvers and innovators who see learning as "an active, dynamic, nonlinear, discovery-based process - more like traveling along a spider web than moving in a straight line from point A to B" (Wagner 2008, p. 179). But few schools or districts are at that level of digital transformation just yet. What is needed are the people, the competencies, and the culture, alongside the strong leadership, resources, and organizational context, to create the change.

\subsection{Implications and Recommendations}

With the increased importance of developing twenty-first-century skills in students, transforming teaching and learning with technology to make progress toward digital transformation is crucial. This work requires efforts to gauge evaluation to determine the ideal combination of technology and instruction to reach learning targets, outcomes, and curricular goals in each unique K-12 organization. Patton (2008) contends that "social science has proven especially inept at offering solutions for the great problems of our time.....There is a pressing need to make headway with these large challenges and push the boundaries of social innovation to make real progress" (p. 28).

There are several implications for theory, methodology, and practice. A helpful framework for considering the factors of digital transformation in K-12 learning organizations and their interconnected systems on the macrolevel is to study the people, organizational culture, and sets of competencies. To further understand the complex interactions between these systems, it is then crucial to apply an inner framework of organizational context, leadership, and available resources. One area in which the boundaries need to be challenged and expanded is in evaluating the extent and impact of technology integration in schools, moving beyond qualitative perception satisfaction surveys, and toward the inclusion of the ISTE Standards, evaluation frameworks, and tools. At this stage of technology integration in Modern Mind CUSD, there has been little to no structure for evaluating the process of digital transformation nor what constitutes effective practices with technology, leaving its potential unrecognized. To truly transform teaching and increase both educator and 
leadership capacity, there must be a shift in current evaluation tools and processes to avoid doing old things in new ways. The Illinois State Board of Education (ISBE) requires that evaluation be grounded in the purposes of accountability, improving system performance, and professional learning. The ISBE also promotes the goal of evaluation as a method to enhance teaching and learning by better preparing students for twenty-first-century society and teachers and leaders to adapt to this type of classroom and school environment (ISBE 2018). Updating current evaluation processes to include the study of technology integration processes and outcomes will provide opportunities for stakeholders to examine professional practice collaboratively to identify strengths, weaknesses, and areas for growth and development.

Evaluation tools and processes that measure the effectiveness of educational technologies will be crucial for measuring progress toward digital transformation and are an important area for future research. Studying the interconnected systems in K-12 organizations of different types may inform the planning and implementation of wide-scale digitally focused change. Studies must consider the key elements of people, competencies, and organizational culture as well as resources, leadership supports, and organizational context. Enhanced evaluation tools and measurement could also promote personalized learning and create a culture of modern learners prepared for the twenty-first century. In K-12 organizational contexts, digital transformation ultimately means the use of available digital tools and technologies to amplify educational outcomes and learner possibilities. If educational technologies are simply layered on top of outdated instructional paradigms, first-order change may occur, but not the second-order change necessary for transformation.

\section{References}

Baker, J. (2012). The technology-organization-environment framework. In Information systems theory. New York: Springer.

BrightBytes. (2019). Turn big data into big benefits for students. Retrieved from https://www. brightbytes.net/

Desimone, L. M. (2009). Improving impact studies of teachers' professional development: Toward better conceptualizations and measures. Educational Researcher, 38(3), 181-199.

Evans, J. M., Grudniewicz, A., Gray, C. S., Wodchis, W. P., Carswell, P., \& Baker, G. R. (2017). Organizational context matters: A research toolkit for conducting standardized case studies of integrated care initiatives. International Journal of Integrated Care, 17(2), 1-10.

Flanagan, L. \& Jacobsen, M. (2003). Technology leadership for the twenty-first century principal. Journal of Educational Administration, 42(2), 124-142.

Fonseca, L. M., \& Domingues, J. P. (2017). How to succeed in the digital age? Monitor the organizational context, identify risks and opportunities, and manage change effectively. Management \& Marketing, 12(3), 443-455.

Garet, M. S., Wayne, A. J., Stancavage, F., Taylor, J., Eaton, M., Walters, K., Song, M., Brown, S., \& Hurlburt, S. (2010). Middle school mathematics professional development impact study: Findings after the first year of implementation [PDF file]. Retrieved from https://ies.ed.gov/ ncee/pubs/20104009/pdf/20104010.pdf

Iovinelli, J. (2020). Into the cloud: How professional development and leadership relate to technology implementation. Dissertations. 441. https://digitalcommons.nl.edu/diss/441 
Illinois State Board of Education [ISBE]. (2018). 5Essentials Survey. Retrieved from https://www. isbe.net/Pages/5Essentials-Survey.aspx

International Society for Technology in Education [ISTE]. (2018). ISTE standards. Retrieved from https://www.iste.org/standards/for-education-leaders

LearningForward. (2011). Standards for professional learning. Retrieved from https://learningforward.org/standards

Mortenson, G., \& Relin, D. O. (2007). Three cups of tea: One man's mission to promote peace one school at a time. New York: Penguin Books

Oliveira, T., \& Martins, M. F. (2011). Literature review of information technology adoption models at the firm level. Electronic Journal of Information Systems Evaluation, 14(1), 110.

OnBase. (2017). Digital transformation: A traveler's guide for the journey [PDF]. Retrieved From https://www.hyland.com/-/media/Files/hyland/ebooks/onbase-product-digital-transformationebook.pdf?la=en

Patton, M. (2008). Utilization-focused evaluation. Thousand Oaks, CA: SAGE Publications, Inc.

Penuel, W. R., Gallagher, L. P., \& Moorthy, S. (2011). Preparing teachers to design sequences of instruction in earth systems science: A comparison of three professional development programs. American Educational Research Journal, 48(4), 996-1025.

Reeves, D. (2009). Leading change in your school: How to conquer myths, build commitment, and get results. Alexandria: Association for Supervision \& Curriculum Development (ASCD).

Ritchie, D. (1996). The administrative role in the integration of technology. National Association of Secondary School Principals. NASSP Bulletin, 80(582), 42-52.

Rogers, E. M. (1995). Diffusion of innovations (4th ed.). New York: Free Press.

Smith, J., \& Smith, R. (2015). Evaluating instructional leadership: Recognized practices for success. Thousand Oaks: Corwin Press.

Tornatzky, L., \& Fleischer, M. (1990). The process of technology innovation. Lexington: Lexington Books.

U.S. Department of Education. (2017). Reimagining the role of technology in education: 2017 National education technology plan update [PDF file]. Retrieved from https://tech.ed.gov/ files/2017/01/NETP17.pdf

Wagner, T. (2008). The global achievement gap. New York: Basic Books.

Wagner, T., Kegan, R., Lahey, L., Lemons, R., Garnier, J., Helsing, D., Howell, A., \& Rasmussen, H. T. (2006). Change leadership: A practical guide to transforming our schools. San Francisco: Jossey-Bass.

Waters, J. T., \& Marzano, R. J. (2006). School district leadership that works: The effect of superintendent leadership on student achievement. Denver: Mid-continent Research for Education and Learning (McREL).

Whitehead, B., Jensen, D., \& Boschee, F. (2013). Planning for technology: A guide for school administrators, technology coordinators, and curriculum leaders. Thousand Oaks: Corwin Press. 
Open Access This chapter is licensed under the terms of the Creative Commons Attribution 4.0 International License (http://creativecommons.org/licenses/by/4.0/), which permits use, sharing, adaptation, distribution and reproduction in any medium or format, as long as you give appropriate credit to the original author(s) and the source, provide a link to the Creative Commons license and indicate if changes were made.

The images or other third party material in this chapter are included in the chapter's Creative Commons license, unless indicated otherwise in a credit line to the material. If material is not included in the chapter's Creative Commons license and your intended use is not permitted by statutory regulation or exceeds the permitted use, you will need to obtain permission directly from the copyright holder. 